\title{
LEVANTAMENTO FITOSSOCIOLÓGICO DE PLANTAS DANINHAS NA CULTURA DA PIMENTA-DO-REINO NA AMAZÔNIA ORIENTAL
}

\author{
Mateus Pantoja Martins ${ }^{1}$, Jefferson dos Santos Martins ${ }^{1}$, Mariana Casari Parreira ${ }^{2}$, Jefferson Bruno \\ Carvalho Soares ${ }^{3}$, Rafael Coelho Ribeiro ${ }^{2}$
}

\begin{abstract}
RESUMO - O cultivo de pimenta-do-reino (Piper nigrum L.) no território brasileiro teve origem na década de 1930 por meio da imigração japonesa, e desde então perdura como um dos principais cultivos agrícolas de interesse econômico na região amazônica. Este trabalho teve como objetivo avaliar a comunidade infestante na cultura da pimenta-do-reino, na região da Amazônia Oriental. As coletas de dados ocorreram em cinco áreas com cultivo de pimenta-do-reino na localidade de Belos Prazeres, zona rural do município de CametáPA. Para a avaliação da comunidade infestante, em cada área de cultivo, foi adotada quatro amostras de 1,0 $\mathrm{m}^{2}$, sendo as plantas daninhas presentes removidas, mensuradas, classificadas. Com base nos dados coletados determinaram-se os índices de densidade, densidade relativa, frequência, frequência relativa, abundância, abundância relativa, massa fresca relativa, índice de valor de importância e o índice de valor de importância relativo. Entre as espécies que compuseram a comunidade infestante nas áreas avaliadas com cultivo de pimenta-doreino, a Spergula arvensis, assim como a Galinsoga parviflora, a Tarenaya spinosa e a Cabomba furcata foram as mais representativas, entretanto $S$. arvensis foi a única espécie que apresentou altos valores em todos os índices fitossociológicos avaliados.
\end{abstract}

Palavras chave: biodiversidade, comunidade infestante, Piper nigrum L.

\section{PHYTOSOCIOLOGICAL SURVEY WEED IN AMAZONIA EASTERN BLACK PEPPER CROP}

\begin{abstract}
The black pepper crop (Piper nigrum L.) in Brazil originated in the 1930s through Japanese immigration and has since continued as one of the main agricultural crops of economic interest in the Amazon. The objective of this work was to evaluate the weed community in the black pepper crop in the Eastern Amazon. Data were collected in five areas with pepper cultivation in Belos Prazeres, a rural area in Cametá municipality, in Pará. For weed community evaluation, four samples were taken in each cultivation area of $1.0 \mathrm{~m}^{2}$. Based on the data collected from invasive species, the phytosociological indexes were determined: density, relative density, frequency, relative frequency, abundance, relative abundance, relative fresh mass, importance value index and relative importance value index. Among the species that composed the weed community Spergula arvensis, as well as Galinsoga parviflora, Tarenaya spinosa and Cabomba furcata were the most significant, integrating most of the parameters analyzed. The specie S. arvensis was the only species to be represented in all evaluated phytosociological indexes.
\end{abstract}

Keywords: biodiversity, Piper nigrum L., weed community.

\footnotetext{
${ }^{1}$ Eng $^{\circ}$ Agr $^{\circ}$ Faculdade de Agronomia (FAGRO).

${ }^{2}$ Prof. Dr. Campus Universitário do Tocantins (CUNTINS). Universidade Federal do Pará. UFPA-Cametá. (mcparreira@ufpa.br)

${ }^{3}$ Doutorando Universidade Federal Rural da Amazônia (UFRA).
} 


\section{INTRODUÇÃO}

A cultura da pimenta-do-reino (Piper nigrum L.) no Brasil teve origem na década de 1930 por meio da imigração japonesa, e desde então perdura como um dos principais cultivos agrícolas de interesse econômico na região amazônica (Duarte, 2006).

A região norte é onde se concentra a maior produção de pimenta-do-reino a nível nacional, com cerca de $76 \%$ (39.540 toneladas) da produção brasileira. Sendo o Pará o estado que apresenta o maior índice de produção, 25,199 toneladas ( $98,1 \%$ da produção da região norte), com área colhida de 16.620 ha (IBGE, 2017).

Uma das principais causas que influenciam a produção de culturas agrícolas como a pimenta-doreino, é a presença de plantas daninhas na área cultivada (Soares et al., 2010). Uma vez que, a flora daninha pode causar danos aos produtores de forma direta, como competição de nutrientes ou indireta como hospedeira de praga e doenças (Brighenti et al., 2010).

Entre os fatores que contribuem para o surgimento de populações de plantas daninhas estão o tipo de manejo empregado nos cultivos e a instauração de plantios próximos a áreas com histórico de infestação oportuna. Onde haverá competição por espaço, água, sais minerais, luz, $\mathrm{CO}_{2}$ e $\mathrm{O}_{2}$ e ainda possivelmente abrigo de insetos-praga e vetores de doenças (Freitas et al., 2006).

Nesse contexto, o conjunto de todas as populações de plantas daninhas que habitam os agroecossitemas ou área definida em função de um objetivo específico de estudo é chamado de comunidade infestante (Pitelli, 2015). Sendo que o passo inicial para o controle dessa sociedade de plantas, comina na identificação prévia de suas respectivas espécies (Pitelli, 2000).

Em vista disso, Concenço et al. (2013), define o estudo fitossociológico como um procedimento metodológico voltado para a análise ecológica de plantas com o objetivo holista de estabelecer a compostura das espécies presentes em um determinado ambiente. Os índices do levantamento fitossociológico confrontam as populações de plantas daninhas em um deliberado tempo e espaço, visando determinar de maneira hierárquica as espécies em função da sua posição relativa às demais, dentro das áreas com culturas agrícolas. Tendo em vista, parâmetros como densidades, frequências, abundâncias e índices de valor de importância (Carvalho et al., 2008), viabilizando com isso a interpretação quantitativa das características e relações ecológicas da comunidade (Gama, 2009).

Assim sendo, este trabalho teve como objetivo avaliar a comunidade infestante, na cultura da pimentado-reino, na região do Baixo Tocantins na Amazônia Oriental.

\section{MATERIAL E MÉTODOS}

O presente trabalho foi desenvolvido em cinco áreas agrícolas de um hectare cada, no qual estavam presentes a cultura de pimenta-do-reino em pleno florescimento. As áreas avaliadas pertenciam a comunidade de Belos Prazeres ( $2^{\circ} 13^{\prime} 23^{\prime \prime} \mathrm{S}-49^{\circ} 15^{\text {, }}$ $55^{\prime}$ 'W), localizada na zona rural do município de Cametá$\mathrm{PA}\left(2^{\circ} 14^{\prime} 32^{\prime \prime} \mathrm{S}-49^{\circ} 29^{\prime} 52^{\prime \prime} \mathrm{W}\right)$, microrregião do Baixo Tocantins, situada na Amazônia Oriental.

Para a avaliação da comunidade infestante, em cada área de cultivo da pimenta do reino (tamanho de aproximadamente de um hectare) foram coletados quatro quadrados amostrais de um metro quadrado cada. Nesses quadrados amostrais as plantas daninhas presentes foram removidas, mensuradas, classificadas e posteriormente pesadas em balança de precisão para obtenção da massa fresca. A identificação das plantas coletadas foi feita através de livros especializados na área e de consultas ao museu Emilio Goeldi (Belém/PA).

Os dados meteorológicos relativos à precipitação pluviométrica, umidade relativa e temperaturas durante o período experimental estão apresentados na Figura 1.

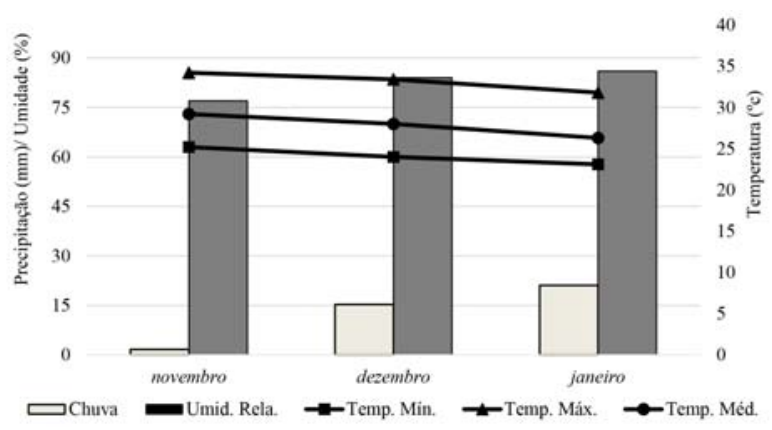

Figura 1 - Precipitação pluviométrica, umidade relativa e temperaturas (máxima, mínima e média) mensais apuradas de novembro de 2017 a janeiro de 2018 em Cametá-PA. 
Com base nos dados coletados das espécies presentes nas áreas analisadas, foram determinados os seguintes índices fitossociológicos: densidade (Den), densidade relativa (DenR), frequência (Fre), frequência relativa (FreR), abundância (Abu), abundância relativa (AbuR), massa fresca relativa (MF) índice de valor de importância (IVI) e o índice de valor de importância relativo (IR).

Foram utilizadas as seguintes fórmulas para o cálculo das variáveis:

$$
\begin{gathered}
\text { Den (plantas . } \left.\mathrm{m}^{-2}\right)=\frac{\text { No total de indivíduos por espécie }}{\text { Área total coletada }} \\
\text { DenR }(\%)=\frac{\text { Densidade da espécie } \times 100}{\text { Densidade total de totas as espécies }} \\
\text { Fre }=\frac{\text { № de parcelas que contém a espécie }}{\text { № total de amostras utilizadas }} \\
\text { FreR }(\%)=\frac{\text { Frequência da espécie } \times 100}{\text { Frequência total de totas as espécies }} \\
\text { Abu }=\frac{\text { No total de indivíduos por espécie }}{\text { No total de parcelas contendo a espécies }} \\
\text { AbuR }(\%)=\frac{\text { Abundância da espécie } \times 100}{\text { Abundância total de totas as espécies }} \\
\text { MF }(\%)=\frac{\text { Massa fresca } \times 100}{\text { Massa fresca total de totas as espécies }} \\
\text { IVI }=\text { Frr }+ \text { Der }+A b r+M f r \\
\text { IVI } \times 100
\end{gathered}
$$

\section{RESULTADOS E DISCUSSÃO}

O levantamento fitossociológico demonstrou que as plantas eudicotiledôneas apresentaram maior percentual $(58,8 \%)$ em relação às monocotiledôneas. Dentre as monocotiledôneas, a família Poaceae foi a mais representativa, com cerca de $32 \%$ da comunidade infestante, seguida pelas famílias Asteraceae com quatro espécies, Euphorbiaceae e Lamiaceae, ambas com duas espécies cada. As demais famílias foram representadas apenas por um indivíduo (Tabela 1).

Da mesma maneira, constatou-se uma acentuada diversidade de plantas daninhas nas cinco áreas estudadas, sendo encontradas 1.134 plantas, representadas em 34 espécies e divididas em 19 famílias botânicas, apresentadas na Tabela 1 .

As plantas eudicotiledôneas são compostas por uma vasta diversificação botânica, sendo elas de vários tamanhos como árvores, arbusto e também ervas. Diante disso, a maioria das espécies vegetais que se tem conhecimento, em torno de 150 mil, estão inclusas neste grande grupo (Lorenzi, 2008).

Nos índices de densidade e densidade relativa as espécies que obtiveram maior relevância foram a Galinsoga parviflora, Spergula arvensis, Ludwigia elegans, Cabomba furcata e Tarenaya spinosa (Figura 2). Desse modo, as espécies G. parviflora e S. arvensis foram as mais representativas, com densidades de 46 e 45,2 plantas. $\mathrm{m}^{-2}$ e densidades relativas de $17,52 \%$ e $17,21 \%$, respectivamente. Seguidas das espécies L. elegans com 38 plantas. $\mathrm{m}^{-2}$ e $14,47 \%$, C. furcata com 27,4 plantas. $\mathrm{m}^{-2}$ e $10,43 \%$ e $T$. spinosa com 19,6 plantas. $\mathrm{m}^{-2}$ e $7,46 \%$.

Segundo Brighenti et al. (2010), a espécie G. Parviflora, nativa da América Tropical, propaga-se exclusivamente por sementes que são facilmente dispersadas pelo vento. É uma planta de ciclo curto, que apresenta viabilidade de sementes no período de quatro semanas, ocorrendo várias gerações no decorrer de um ano.

Esta espécie encontra-se em grande parte dos solos cultivados do território nacional, com isso, se estabelece relação com várias culturas de interesse econômico como olerícolas e pomares. Ela se instala nas áreas cultivadas passando a competir por espaço, luz e nutrientes, podendo hospedar pragas (nematoides) e doenças (vírus) (Moreira \& Bragança, 2011).

Quanto à frequência e frequência relativa as espécies que se sobressaíram foram a Digitaria bicornis, Spergula avensis, Phyllanthus amarus, Galinsoga parviflora e Cabomba furcata (Figura 3). Com isso, a espécie D. bicornis, superou as demais com o quantitativo 1 para frequência absoluta e $8,47 \%$ para frequência relativa. No mais, as espécies $S$. arvensis e P. amarus apresentaram os mesmos valores de frequência absoluta $(0,8)$ e frequência relativa $(6,78 \%)$, assim como também as espécies G. parviflora e C. furcata foram similares nestes índices, ambas com 0,6 e 5,08\%.

A D. bicornis é comumente encontrada em todo Brasil, sendo uma das espécies mais representativas do gênero Digitaria (Dias et al., 2007). Além de se 
Tabela 1 - Comunidade infestante presente nas áreas com o cultivo de pimenta-do-reino. Belos Prazeres, Cametá-PA

\begin{tabular}{|c|c|c|c|}
\hline Família & Nome científico & Nome popular & \\
\hline Amaranthaceae & Amaranthus spinosus L. & Caruru-de-espinho & Eudicotiledônea \\
\hline Araceae & Caladium bicolor (Aiton) Vent. & Tamba-tajá & Monocotiledônea \\
\hline \multirow[t]{4}{*}{ Asteraceae } & Galinsoga parviflora Cav. & Botão-de-ouro & Eudicotiledônea \\
\hline & Physalis angulata $\mathrm{L}$. & Camapú & \\
\hline & Praxelis diffusa (Rich.) Pruski & Couve cravinho & \\
\hline & Cabomba furcata Schult. \& Schult.f. & Rabo-de-raposa & \\
\hline Boraginaceae & Heliotropium indicum L. & Crista-de-galo & Eudicotiledônea \\
\hline Brassicaceae & Tarenaya spinosa (Jacq.) Raf. & Mussambê & Eudicotiledônea \\
\hline Caryophyllaceae & Spergula arvensis L. & Esparguta & Eudicotiledônea \\
\hline Commelinaceae & Escallonia bífida Link \& Otto & Maria-mole & Monocotiledônea \\
\hline Cyperaceae & Eleutherine bulbosa (Mill.) Urb. & Tiriricão & Monocotiledônea \\
\hline \multirow[t]{2}{*}{ Euphorbiaceae } & Euphorbia hirta L. & Erva de Santa Luzia & Eudicotiledônea \\
\hline & Astraea lobata (L.) Klotzsch & Erva-de-Rôla & \\
\hline Fhyllanthaceae & Phyllanthus amarus Schumach. & Quebra pedra & Eudicotiledônea \\
\hline \multirow[t]{2}{*}{ Lamiaceae } & Marsypianthes chamaedrys (Vahl) Kuntze & Betônica-brava & Eudicotiledônea \\
\hline & Hyptis lophantha Mart. ex Benth. & Catirina & \\
\hline Loganiaceae & Elaeoluma glabrescens (Mart. \& Eichler) Aubrév. & Llombrigueira & Eudicotiledônea \\
\hline Lythraceae & Symplocos tetrandra Mart. & Sete-sangria & Eudicotiledônea \\
\hline Malvaceae & Malvastrum coromandelianum Garcke & Malvastro & Eudicotiledônea \\
\hline Onagraceae & Ludwigia elegans (Cambess.) H.Hara & Cruz-de-malta & Eudicotiledônea \\
\hline Plantagenaceae & Scoparia dulcis L. & Vassourinha & Eudicotiledônea \\
\hline \multirow[t]{11}{*}{ Poaceae } & Panicum cyanescens Nees ex Trin. & Capim azul & Monocotiledônea \\
\hline & Eragrostis curvula (Schrad.) Nees & Capim chorão & \\
\hline & Brachiaria plantaginea (Link) Hitchc. & Capim marmelada & \\
\hline & Brachiaria purpurascens (Raddi) Henrard & Capim-angola & \\
\hline & Echinochloa crus-pavonis (Kunth) Schult. & Capim-arroz & \\
\hline & Cynodon dactylon (L.) Pers. & Capim-bermuda & \\
\hline & Sporobolus indicus (L.) R.Br. & Capim-capeta & \\
\hline & Digitaria bicornis (Lam.) Roem. \& Schult. & Capim-colchão & \\
\hline & Pennisetum clandestinum Hochst. ex Chiov. & Capim-kikuio & \\
\hline & Axonopus scoparius (Flüggé) Kuhlm & Imperial & \\
\hline & Lolium temulentum L. & Joio & \\
\hline Molluginaceae & Mollugo verticillata $\mathrm{L}$. & Capim-tapete & Eudicotiledônea \\
\hline Rubiaceae & Borreria verticillata (L.) G.Mey. & Vassourinha-de-botão & Eudicotiledônea \\
\hline
\end{tabular}

\section{Den e Den R}

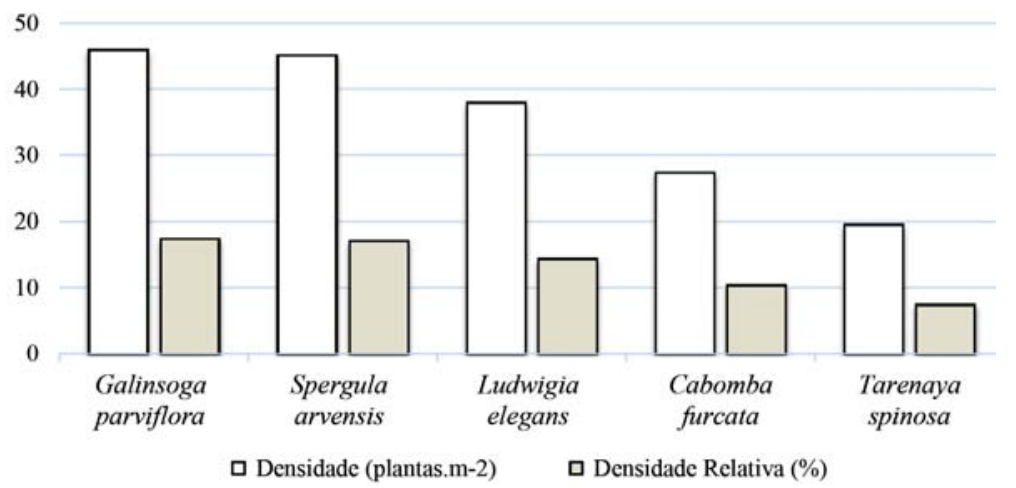

Figura 2 - Densidade (Den) e densidade relativa (DenR) das cinco espécies mais representativas encontradas nas cinco áreas com cultivo de pimenta-do-reino. Belos Prazeres, Cametá-PA. 


\section{Fre e FreR}

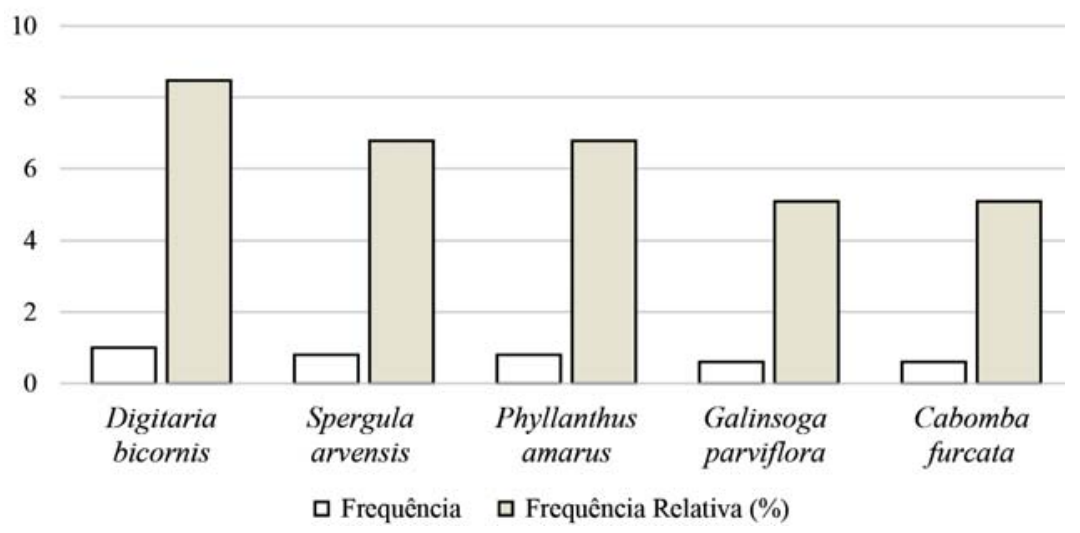

Figura 3 - Frequência (Fre) e Frequência relativa (FreR) em percentual, das cinco espécies mais relevantes encontradas nas cinco áreas com cultivo de pimenta-do-reino. Belos Prazeres, Cametá-PA.

desenvolver na região da Amazônia Oriental, ela também, de acordo com Moreira \& Bragança (2011), se estabelece nas regiões centro-oeste, sul e sudeste podendo formar densas populações chegando a dominar áreas de cultivos anuais e perenes.

Do mesmo modo Kissmann (1997), também descreve que espécies da família Poacea (D. bicornis) são altamente agressivas como infestantes, pois são bastante competitivas, além de apresentarem efeitos alelopáticos sobre diversas culturas que contribuem para a geração de problemas na produção principalmente de cultivos anuais e semi-perenes.

Com exceção da espécie Axonopus scoparius, todos os indivíduos relatados na avaliação de densidade e densidade relativa foram idênticos nos índices de abundância (Abu) e abundância relativa (AbuR). Ou seja, as cinco espécies que apontaram os maiores valores foram a Ludwigia elegans, Galinsoga parviflora, Spergula arvensis, Axonopus scoparius e Tarenaya spinosa (Figura 4).

A espécie L. elegans liderou os índices de abundância e abundância relativa com os valores 95 e $16,2 \%$, respectivamente. Em seguida, em ordem decrescente, figuraram a G. parviflora com 76,67 e $13,07 \%$, S. avensis com 56,5 e 9,64\%, A. scoparius com 52 e $8,88 \%$ e a $T$. spinosa com 49 e $8,36 \%$.

Assim como a maioria das plantas daninhas encontradas nas áreas avaliadas, a L. elegans também é uma espécie que se desenvolve em todo o território nacional, vegetando em áreas úmidas ocupadas por lavouras anuais ou perenes. Sendo uma potencial hospedeira de insetos vetores de viroses, contribuindo desta forma para a geração de perdas significativas em cultivos agrícolas (Moreira \& Bragança, 2011).

Em referência à massa fresca relativa (MF) as espécies mais representativas foram a Spergula arvensis, Tarenaya spinosa, Marsyanthes chamaedrys, Phyllanthus amarus e Cabomba furcata (Figura 5). Sendo que a espécie $S$. arvensis suplantou as demais neste índice com o valor $(16,27 \%)$ duas vezes maior que o da última espécie (C. furcata), entre as cinco mais relevantes. As demais espécies T. spinosa, M. chamaedrys, $P$. amarus e C. furcata apresentaram valores percentuais de $14,57 \%, 11,88 \%, 11,86 \%$ e $6 ; 41 \%$, respectivamente.

Conforme relatado por Marchioretto et al. (2010), a espécie $S$. arvensis, pertencente à família Caryophyllaceae, frequentemente ocorre em ambientes campestres e antropizados. E apesar desta espécie apresentar comportamento de planta daninha, outros integrantes da sua família destacam-se pelo seu valor econômico ao serem utilizados no ramo ornamental (Souza \& Lorenzi, 2005).

As espécies mais expressivas no índice de valor de importância (IVI) e consequentemente no índice de valor de importância relativo (IR) foram a Spergula arvensis (49,9 e 12,47\%), Ludwigia elegans (39,67 e 9,92\%), Galinsoga parviflora (36,07 e 9,02\%), Tarenaya spinosa (33,78 e 8,45\%) e Cabomba furcata $(29,72$ e 


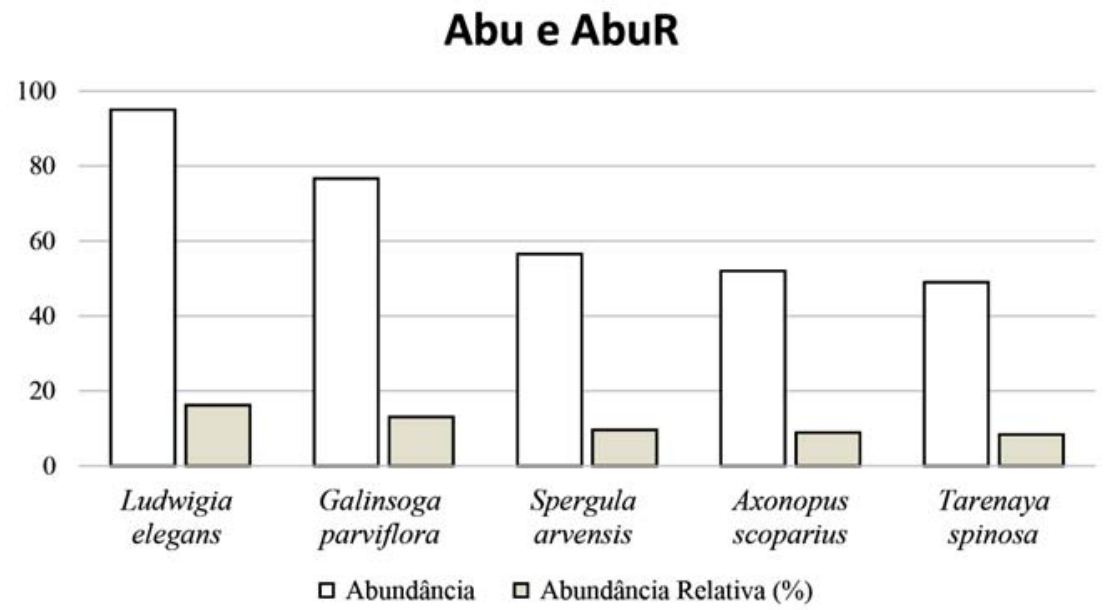

Figura 4 - Abundância (Abu) e abundância relativa (AbuR) em percentual, das cinco espécies mais relevantes encontradas nas cinco áreas com cultivo de pimenta-do-reino. Belos Prazeres, Cametá-PA.

\section{Massa Fresca Relativa}

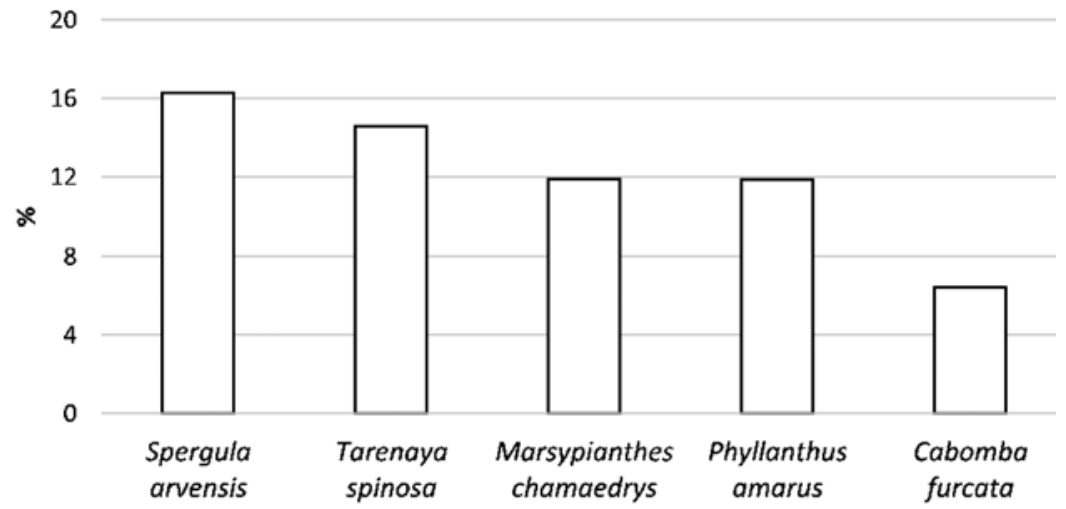

Figura 5 - Massa fresca relativa (MF) das cinco espécies mais relevantes encontradas nas cinco áreas com cultivo de pimenta-do-reino. Belos Prazeres, Cametá-PA.

7,43\%), representadas na Figura 6. Isso ocorreu em virtude do IVI e do IR estarem diretamente relacionados aos índices anteriormente descritos, haja vista que, as cinco espécies citadas predominaram no restante dos parâmetros avaliados.

A espécie $S$. arvensis, planta anual, ereta ou ascendente, de 20 a $50 \mathrm{~cm}$ de altura com caules e ramos suculentos que formam uma densa massa de vegetação sobre o solo, prevaleceu entre as três mais significativas em todos os índices avaliados (Figuras 2, 3, 4, 5 e 6). Seguida pela $L$. elegans que não foi expressiva nos índices de frequência (Fre), frequência relativa (FreR) e massa fresca relativa (MF) (Figuras 3 e 5), mas, se sobressaiu nos índices de abundância (Abu) e abundância relativa (AbuR) (Figura 4). Esta espécie possui características de planta herbácea, ereta com 30 a $50 \mathrm{~cm}$ de altura, pigmentada e se reproduz por meio de sementes (Lorenzi, 2008).

Por sua vez, a espécie G. parviflora apresentou relevância nos índices de densidade (Den), densidade relativa (DenR), frequência (Fre), frequência relativa (FreR), abundância (Abu) e abundância relativa (AbuR) 


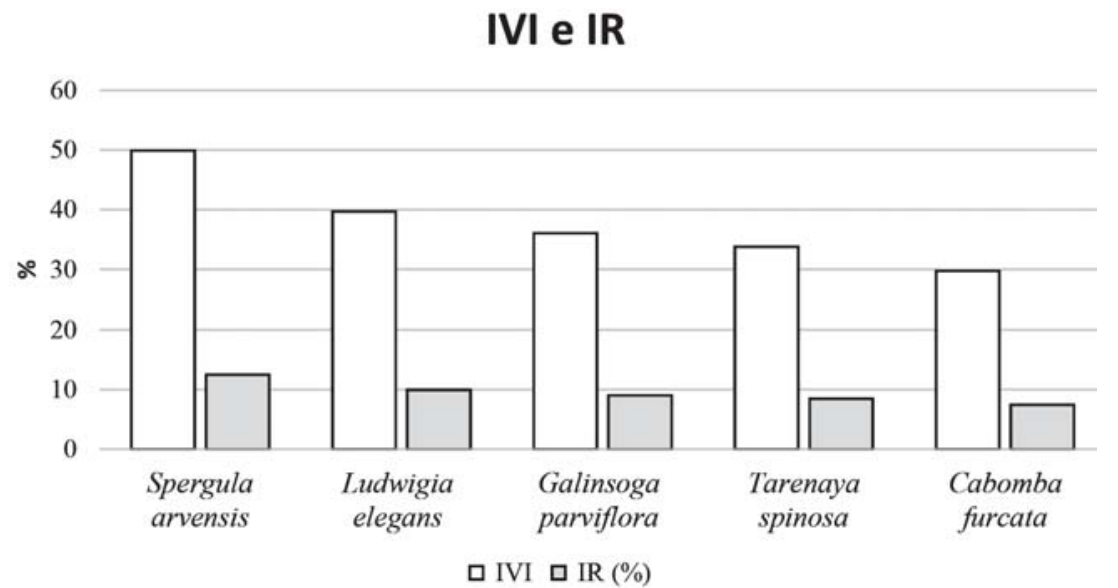

Figura 6 - Índice de valor de importância (IVI) e índice de valor de importância relativo (IR) das cinco espécies mais relevantes encontradas nas cinco áreas com cultivo de pimenta-do-reino. Belos Prazeres, Cametá-PA.

(Figuras 2, 3 e 4), porém, não obteve representatividade no parâmetro massa fresca relativa (MF) (Figura 5). Esta espécie de planta daninha frequentemente encontrada em cultivos anuais ou perenes é altamente competitiva e forma compostos alelopáticos que comprometem o desenvolvimento de outras plantas ao seu redor (Moreira \& Bragança, 2011).

Posteriormente, a T. spinosa apresentou importância nos índices de densidade (Den), densidade relativa (DenR), abundância (Abu), abundância relativa (AbuR) e massa fresca relativa (MF) (Figuras 2, 4 e 5), não sendo relevante apenas nos índices de frequências (Fre) e FreR (Figura 3). Esta planta anual, com espinhos, medindo cerca de 30 a $50 \mathrm{~cm}$ de altura (Lorenzi, 2006), pertencente à família Brassicacea que inclui aproximadamente 400 gêneros e 4000 espécies, é comumente utilizada como planta ornamental de considerável valor econômico (Souza \& Lorenzi, 2005).

Por fim, a espécie $C$. furcata não demonstrou representatividade apenas nos índices de abundância (Abu) e AbuR (Figura 4), sendo significativa nos índices de densidade (Den), densidade relativa (DenR), frequência (Fre), frequência relativa (FreR) e massa fresca relativa $(\mathrm{MF})$ (Figuras 2, 3 e 5). Pertencente à família Asteraceae, que se caracteriza como uma das principais famílias de plantas invasoras (Souza \& Lorenzi, 2005), a C. furcata é uma espécie herbácea anual que se desenvolve em grande parte do território nacional, vegetando em áreas com cultivos anuais ou perenes (Moreira \& Bragança, 2011).

\section{CONCLUSÃO}

Entre as espécies que consistiram a comunidade infestante nas áreas avaliadas com cultivo de pimenta-do-reino, a Spergula arvensis, assim como a Galinsoga parviflora, a Tarenaya spinosa e a Cabomba furcata foram as mais significativas, integrando a maioria dos parâmetros analisados. Sendo que a $S$. arvensis foi a única espécie a ser representada em todos os índices fitossociológicos avaliados, com altos valores.

\section{LITERATURACITADA}

BRIGHENTI, A.M. Manual de identificação e manejo de plantas daninhas em cultivos de cana-de-açúcar. Juiz de Fora: Embrapa Gado de Leite, 2010. 112p.

CARVALHO, L.B. et al. Interferência e estudo fitossociológico da comunidade infestante em beterraba de semeadura direta. Planta Daninha, v.26, n.2, p.291-299, 2008.

CONCENÇO, G. et al. Phytosociological surveys: tools for weed science? Planta Daninha, v.31, n.2, p.469-482, 2013.

DIAS, A.C.R. et al. Problemática da ocorrência de diferentes espécies de capim-colchão (Digitaria spp.) na cultura da cana-de-açúcar. Planta daninha, v.25, n.3, p.489-499, 2007. 
DUARTE, M.L.R. et al. A cultura dapimenta-do-reino. $2^{\mathrm{a}} \mathrm{Ed}$. Brasília, DF: Embrapa Informação Tecnológica, 2006. Coleção Plantar, 55. 73p.

FREITAS, R.S. et al. Manejo de plantas daninhas na cultura do algodoeiro em sistema de plantio direto. Planta daninha, v.24, n.2, p.339-346, 2006.

GAMA, J.C.M. Florística e Fitossociologia de Plantas Espontâneas em

Comunidades Antropizadas do

Cerrado em Minas Gerais. 106f.

Dissertação (Mestrado), Universidade Federal de Minas Gerais - UFMG, 2009.

INSTITUTO BRASILEIRO DE GEOGRAFIA E ESTATÍSTICA - IBGE. Censo demográfico: sinopse. Brasil, 2017.

KISSMANN, K.G. Plantas infestantes e nocivas. 2.ed. São Paulo: BASF, 1997. 978p.

LORENZI H. Plantas daninhas do Brasil: terrestres, aquáticas, parasitas e tóxicas. $4^{\mathrm{a}}$. ed. Nova Odessa: Instituto Plantarum, 2008. 640p.
MARCHIORETTO, M.S. et al. Análise da distribuição geográfica da família Caryophyllaceae no rio grande do sul. Pesquisas Botânicas, v.61 n.1, p.205-218, 2010.

MOREIRA, H.J.C.; BRAGANÇA, H.B.N. Manual de identificação de plantas infestantes: Arroz. Campinas: FMC, 2011.854p.

PITELLI, R.A. O termo planta-daninha. Planta Daninha, v.33, n.3, 2015.

PITELLI, R.A. Estudos fitossociológicos em comunidades infestantes de agroecossistemas. J. Conseb, v. 1, n.3, p.1-7, 2000.

SOARES, I.A.A et al. Interferência das plantas daninhas sobre a produtividade e qualidade de cenoura. Planta Daninha, Viçosa-MG, v.28, n.2, p.247-254, 2010.

SOUZA, V.C.; LORENZI, H. Botânica sistemática: guia ilustrado para identificação das famílias de Angiospermas da flora brasileira, baseado em APG II. Nova Odessa: Instituto Plantarum, 2005. 640p.

Recebido para publicação em 2/5/2018 e aprovado em 10/10/2018. 